\title{
Comparisons of Line Transect and Point Count Survey Methods by Estimating Density of Grey Squirrel Sciurus Carolinensis
}

\author{
Mariwan Rahim (Corresponding author) \\ Environment Directorate of Sulaimani \\ Ashti Quarter, As Sulaymaniyah 46001, Iraq \\ Tel: 964-770-191-2613Ｅ-mail: biomariwan@gmail.com
}

Received: April 9, 2016 Accepted: April 20, 2016 Published: June 18, 2016

doi:10.5296/jee.v7i1.9287 URL: http://dx.doi.org/10.5296/jee.v7i1.9287

\begin{abstract}
The methods have used to study animal population must be defined clearly at the beginning of the project. We compared line transect and point count survey methods to estimating the density of grey squirrel at University of East Anglia campus (UEA), Norwich-United Kingdom. Across the entire UEA campus we surveyed 0.43698 ha of the 146 ha of the campus area. A total of 21 squirrels were observed during survey between $21^{\text {st }}-26^{\text {th }}$ in December 2013. Nine individuals were observed during line transect and twelve individuals were observed during point counts. The average number of species detected was differing between the two methods. Density estimates of grey squirrel from the two methods were different. Densities of grey squirrel as estimated by point count surveys were higher than those by line transect count surveys. Our results indicate that it is important to account for different survey methods when comparing the two methods to estimate the grey squirrel.
\end{abstract}

Keywords: Ecological technique, Biodiversity, Wildlife 


\section{Introduction}

The methods have used to study animal population must be defined clearly at the beginning of the project (Southwood and Henderson 2000). The size of the species and its natural history has important role to determine the census methods of mammals, when the species are nocturnal, rare and difficult to detect during survey, the counting problem will be difficult, while, if species are diurnal, common and highly visible, the census problem is moderately simple. So you need to decide the aim of the study and the level of precision your work is required as in all ecological survey work. Therefore the project with higher precision required high cost in money and time, for some work it is not practical within a limited budget and time (Sutherland.W.J. 2006).

To estimate the abundance of wildlife population, line transect method has been used for nearly 50 years(Hayne 1949). The methods is used to estimate the unknown population size by walking distance across a path of area in line, count the number of animals sighted for each species being inspected (Charles E. Gates 1968). On both sides of the area can recode the animal, but sometime can recode in one side. The observer should walk satisfactorily slowly to detect all the animals on the transect line (Sutherland.W.J. 2006). While point count is that, the observer may move to a number of fixed points and record the distance to individual animals. The observer need only estimate distance and markers may be placed in advance to aid the estimation of distance so the point transects are often easier to undertake (Southwood and Henderson 2000).

The North American grey squirrel has colonized the England, Wales and Scottish lowland in the last century; the center of colonization was that at Woburn Abbey in Bedfordshire (Okubo, Maini et al. 1989). This colonization has impact on England biodiversity especially birds and other wildlife, which is confirm recently in Great Britain (Tattoni, Preatoni et al. 2006). In addition, grey squirrel be reservoirs for disease and may prey on birds or bird eggs and it may cause some damage to trees and vegetation. Furthermore it may be impact on telephone cables and electrical power to cut it. Therefore, biologist have special program to control them(Hein 1997). The major factors of this colonization are good habitat and abundant of food sources (Tattoni, Preatoni et al. 2006). Studying or managing squirrel population in forest and woodland is needed to practical survey and monitoring techniques. To detect significant changes in the distribution or abundance of population and species can be used study methods systematically to establish the presence of squirrels in a particular area. The forest mangers are used gray squirrels (Sciurus carolinensis) as a habitat indicator species (Healy and Welsh 1992). Therefore, to evaluate the effects of anthropogenic activity they estimated gray squirrel population density (e.g., habitat management). However, methods to estimate gray squirrel density can be effort intensive and expensive (Barkalow Jr, Hamilton et al. 1970, Nixon, McClain et al. 1975, Healy and Welsh 1992).

There are many methods that used to estimate gray squirrel such as mark-recapture and various survey methods (Flyger 1959, Barkalow Jr, Hamilton et al. 1970, Nixon, McClain et al. 1975) also line-transect used for sampling (Healy and Welsh 1992). Drays or tree nest, which is build by squirrel in trees can be censured by counting these structure using line 
transect or quadrat methods (Sutherland.W.J. 2006). As indices to relative abundance the time area searches and the number of harvested squirrels per unit area can be used as censured methods also (Hein 1997). In addition, the hair tubes are used to survey the grey squirrel, which is a long tube with sticky tape on the inside, the hairs are left on the end that the animal pass through the tube, also the diameter of the tube is lager with the size of the species being study (Sutherland.W.J. 2006). According to Gurnell J (2009) five indirect survey techniques are described, which are based on either sightings or signs of squirrels, and advice is given on their suitability for different types of habitat at different times of the year such as Visual surveys, Hair-tube surveys, Dray counts, Feeding sign surveys and Whole maize bait. However, each method has its bias, therefore it depend on the study purpose with consideration of budget and time of the study can choose the survey methods. In this study we hypothesized that there is a differences between the lines transect and point count (Sutherland.W.J. 2006). By estimating grey squirrel (Sciurus carolinensis) in the University of East Anglia campus. This hypothesis predicts that we will see the number of squirrel observed from line transect higher than point count.

\section{Methods}

\subsection{Study Site}

Study was conducted from $21^{\text {st }}$ to $26^{\text {th }}$ of December 2013 , on the University of East Anglia campus (UEA), which is located in the western edge of Norwich city. The area of the campus is 146 hectares (ha), which is characterized by gently rolling hills to flat open areas and is dominated by mature trees such as pine and oak with an understory of mixed shrubs, flowers, and grass. Also there is a lake in the southern part of the campus. Furthermore, there is a patch of forest in the western part of the campus. The study was designated fully randomized around the UEA campus. The counting was conducted during the late morning and afternoon, during this time most grey squirrel was appeared and active more frequently to search foods and wormer in temperature. The weather of day survey was mostly cloudy and the temperature between $4-8{ }^{\circ} \mathrm{C}$, without precipitation, and slightly windy.

\subsection{Experimental Protocol}

The survey was started by doing 6 line transect with 12 point count which is randomly chose it, for each day I have done one transect $50 \mathrm{~m}$ length with $10 \mathrm{~m}$ width for each side for five minuets (Hein 1997), and with two point counts 5 minutes for each point count with $20 \mathrm{~m}$ diameter for point count circle. So transect line count total ( 6 days* $1=6$ transect line counts), Point counts total (6 days $* 2=12$ point counts) (Figure 1.). 

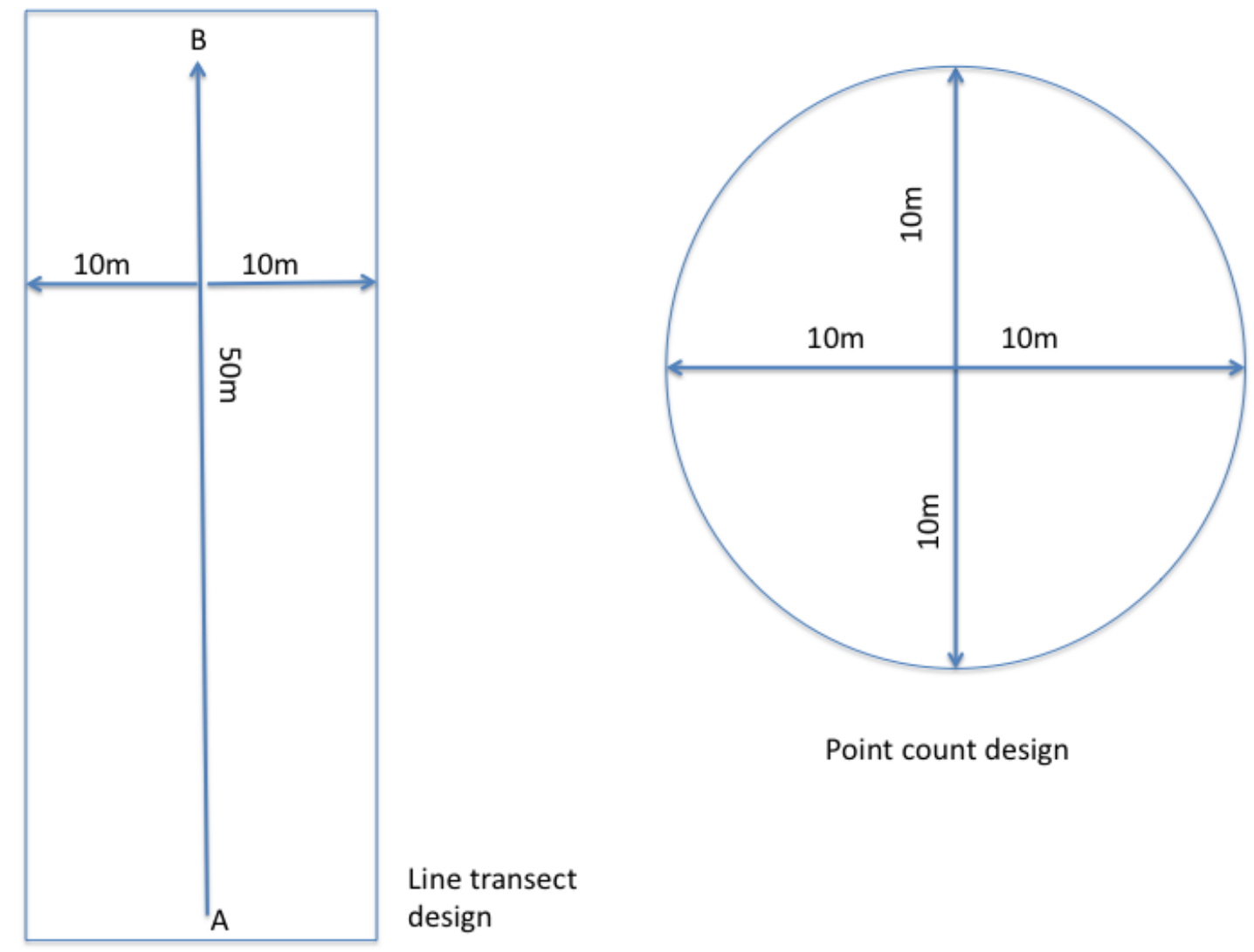

Point count design

Figure 1 . The point count $(\mathrm{r}=$ radius $=10 \mathrm{~m})$ and line transect $(\mathrm{W}=$ belt width $=10 \mathrm{~m}$, $\mathrm{L}=$ Length $=50 \mathrm{~m}$ ) methods design in the UEA campus, Norwich, United Kingdom.

\subsubsection{The Density of Grey Squirrel by Line Transect was Calculated as Follows}

Nine squirrel have observed the data having been pooled together from 6 walks along a $50 \mathrm{~m}$ Length (L), i.e. $1=6 x 50=300 \mathrm{~m}$. The belt width $(\mathrm{w})$ is taken as the point where the number of detections drops to approximately half the previous interval, about $10 \mathrm{~m}$. The number of squirrels seen within $10 \mathrm{~m}$ either side of the line (n) is 9. The density (D) of squirrel is calculated using the equation D =n/2WL (Southwood and Henderson 2000).

$\mathrm{D}=9 /(2 * 10 * 300)=0.0015$ squirrels per $\mathrm{m} 2$ or $\sim 15$ squirrels per hectare.

But the area of UEA campus is $146 \mathrm{~h}$.

$\mathrm{D}=15 * 146=2190$ squirrel per 146 hectare.

\subsubsection{The Density of Grey Squirrel by Point Count was Calculated as Follows}

Instead of navigating a transect, the observer may move to a number of fixed points and record the distance, $r$, to individual animals. Point counts are often easier to start because the observer need only estimate distance.

The density (D) of squirrel is calculated using the equation $\mathrm{D}=\mathrm{n} / \pi \mathrm{kr}^{2}$ (Buckland, Anderson et al. 2004) 
Where $\mathrm{n}$ is the number of animals observed, $\mathrm{k}$ the number of point transects undertaken.

$\mathrm{D}=12 / 3.14 * 12 * 10^{2}=0.00318$ squirrels per $\mathrm{m}^{2}$ or $\sim 31$ squirrels per hectare.

But the area of UEA campus is $146 \mathrm{~h}$.

$\mathrm{D}=31 * 146=4526$ squirrel per 146 hectare

To measure the length of line transect and point count diameter, I used my step as one meter with nature landmark and for starting and ending each point I was taken coordinator (GPS), then I put the coordinator to Google Earth software and getting the measurement by using ruler tools to measure between the start and end points for each site survey (line transect or point count) and compare with my step measure (Figure 2.). Furthermore, I was used free GPS application for smartphone to get the coordinator with Canon 550D camera, and SPSS software (version 21 for Mackintosh).

\subsection{Statistical Analysis}

\subsubsection{Assumption}

1-There should be no significant outliers in the two groups of your independent variable in terms of the dependent variable.

2-Your dependent variable should be approximately normally distributed for each group of the independent variable.

3-You have homogeneity of variances (i.e., the variance is equal in each group of your independent variable)

For statistical analysis, the data were calculated the line transects method and point count to comparing two methods by estimate the grey squirrel number. Used boxplot to assess there were no outliers in the data. Grey squirrel for both point count and line transect count were normally distributed, as assessed by Shapiro-Wilk's test and there was homogeneity of variances, as assessed by Levene's test for equality of variances. Finally used independent t-test to compare between the mean of squirrel counted by each methods. 


\section{$\Lambda$ Macrothink}

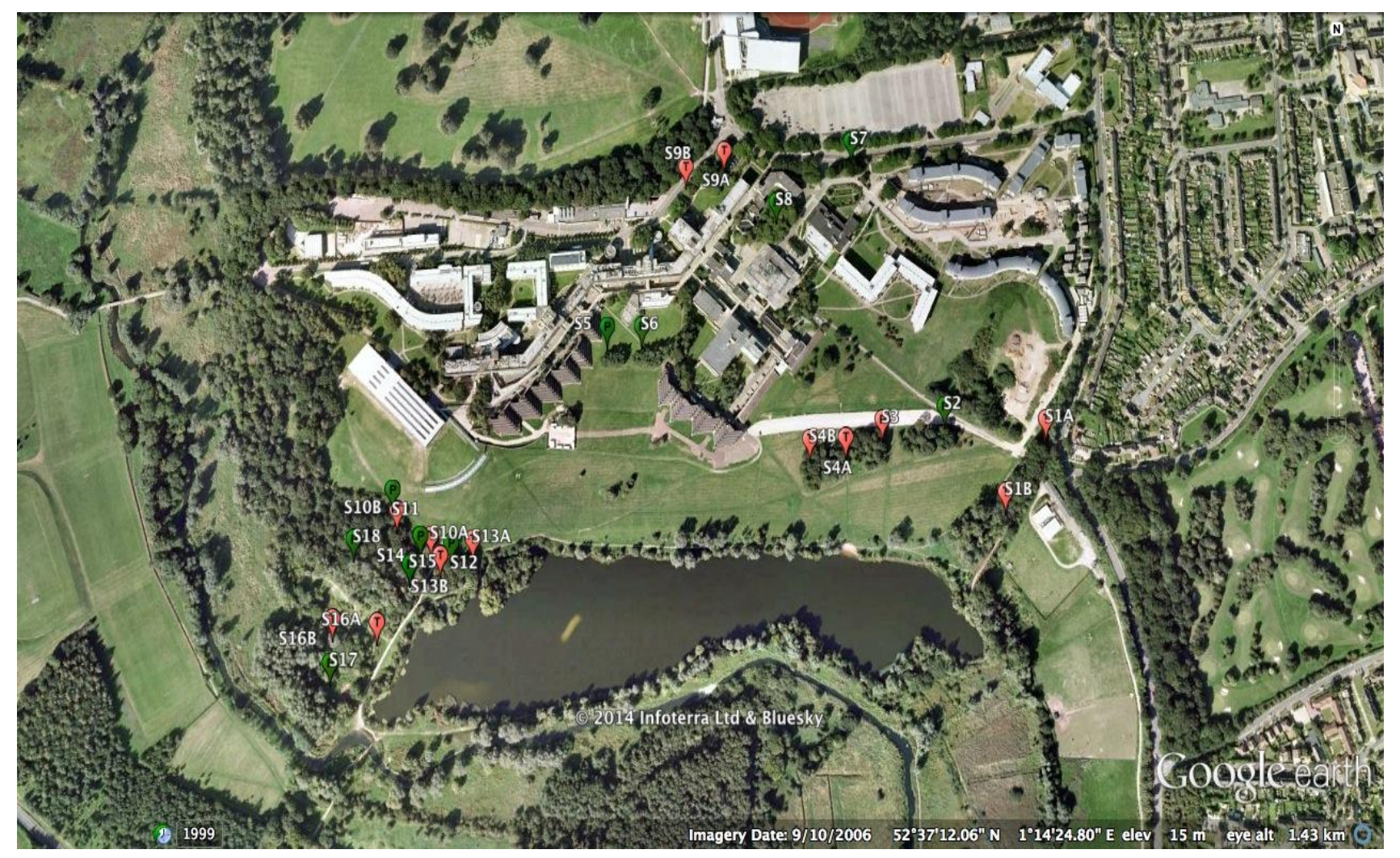

Figure 2. Eighteen sample sites for survey of grey squirrel, each site represented by $\mathrm{S}$ within its number, for Transect (T red-color icon) and for point count (P-green icon) in the UEA campus Norwich, United Kingdom.

\section{Results}

Across the entire UEA campus we surveyed 0.43698 ha of the 146 ha of the campus area and twenty one of squirrels were observed during survey between $21^{\text {st }}-26^{\text {th }}$ in December2013, 9 individual were observed during line transect and 12 individual were observed during point counts. There were 12-point counts (counted as 6-point) and 6 lines transect have used to survey grey squirrel. An independent-samples t-test was run to determine if there was differences between the point count and line transect count methods to estimate grey squirrel. There were no outliers in the data, as assessed by inspection of a boxplot. Grey squirrel for both point count and line transect count were normally distributed, as assessed by Shapiro-Wilk's test $(\mathrm{p}>.05)$, and there was homogeneity of variances, as assessed by Levene's test for equality of variances $(\mathrm{p}=0.599)$. The grey squirrel was more recorded in point count $(\mathrm{M}=2, \mathrm{SD}=1.789)$ than line transect method $(\mathrm{M}=1.5, \mathrm{SD}=1.378)$ (Figure 3.), there is not a significant difference between point count and line transect, $\mathrm{M}=0.5,95 \% \mathrm{CI}$ $[-1.55,2.55], \mathrm{t}(10)=0.542, \mathrm{P}>0.05(\mathrm{p}=0.599)$. Finally the density estimating of grey squirrel by line transect is 15 individuals/ha; while in the point count is 31 individuals/ha. 


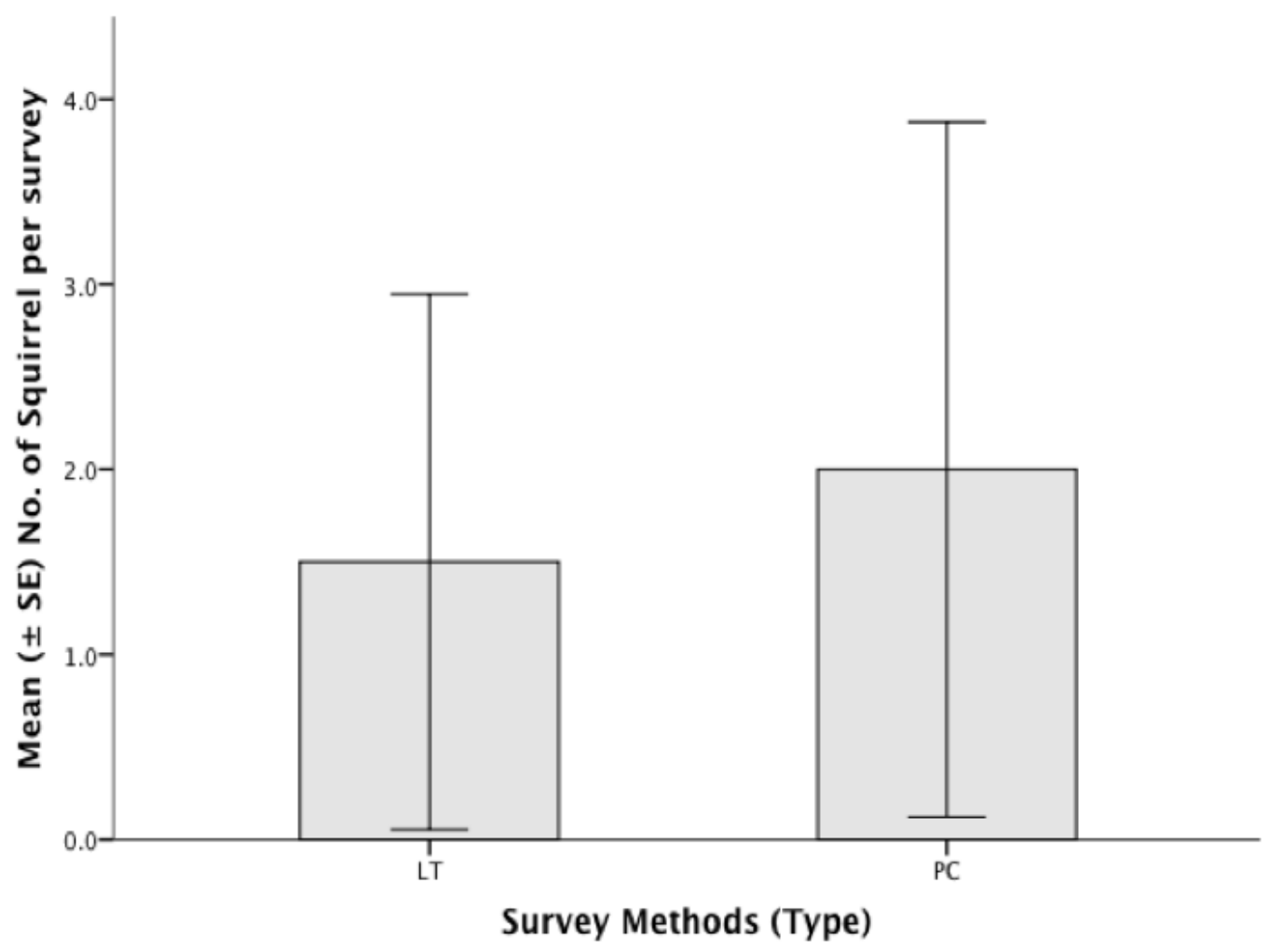

Figure 3. The number of grey squirrels were counted by line transect (LT) and point count (PC) in the UEA campus, Norwich, United Kingdom. Bar Height indicated the mean ( \pm $\mathrm{SE}$ ) of squirrel counted Error Bars: $95 \% \mathrm{CI}$.

\section{Discussion}

This is one of the study that comparing the survey methods for small mammal. Our results show that there are not differences between the methods for survey species especially for small mammals. The results of survey 18 sites in the UEA campus for grey squirrels are twenty-one individuals were observed, in the line transect observed nine individuals, while in the point count observed twelve individuals. As a result of this survey indicated that there is not significant differences between two methods by running independent t-test with SPSS version 21 for Mackintosh $\left(\mathrm{t}{ }_{(10)}=0.542, \mathrm{P}>0.05(\mathrm{p}=0.599)\right.$ for counting grey squirrel. Nevertheless, the estimation density of grey squirrel by two methods are different; by line transect is 15 individuals/ha, while in the point count is 31 individuals/ha. The grey squirrel was more recorded in point count $(\mathrm{M}=2, \mathrm{SD}=1.789)$ than line transects method $(\mathrm{M}=$ $1.5, \mathrm{SD}=1.378$ ) (Figure 3.). Squirrel numbers can be differ broadly through space and time as they follow the accessibility to food sources, therefore the survey and monitoring of grey squirrel can be hard. Population densities can be very low in opened area, typically less than one squirrel per hectare in UEA campus especially. The sample size of sightings and signs of animals tend to be small, therefore low densities make it very hard to estimate population 


\section{Macrothink}

abundance accurately as in my project, the sample size is low, so it affects on my data accurately. (Gurnell J 2009). A density of 15 gray squirrel/ ha by line transect on University of East Anglia campus is lower than the density of grey squirrel were observed by point count 31 gray squirrel/ ha.

According to Hein (1997), "Healy and Welsh (1992) suggested the number of squirrels observed per kilometer of line transect (i.e., the encounter rate) as a relative index of abundance, but Burnham and others (1981) proved that the number of objects seen during line transect surveys is a poor index of abundance and density. The encounter rate can be used to calculate the sample size required to meet the precision of study objectives (Burnham and others 1980, Buckland and others 1993) and may also be used to compare effort between studies of the same species using line transect surveys".

There are some climates variables have effect on the activity of grey squirrel. Squirrels are unlikely to be very active in heavy rain, strong winds or when it is very cold for instance temperature, especially in the winter season, when my project was done in December, Also the grey squirrel is strictly a diurnal species (Thompson 1977).

The suitable time for the activity of grey squirrel at the early morning and late evening in order to find food, they are active during the winter, eating food substances and stored in hundreds of locations throughout their home range (Barker and Boonstra 2005). But in winter season because of low in temperature and cold weather the squirrel can be active at late morning and afternoon, as I did my project at late morning and afternoon to decrease the bias of weather variables. When the temperature was between $4-8{ }^{\circ} \mathrm{C}$ during the survey, which is quite cold but the squirrel was activated to find foods (Figure 4.). While, the weather was slightly windy but some times the wind was strong, in addition to sunshine and most of the days of the survey were mostly cloudy. 


\section{MInstitute ${ }_{\text {Mnk }}^{\text {Macrothink }}$}

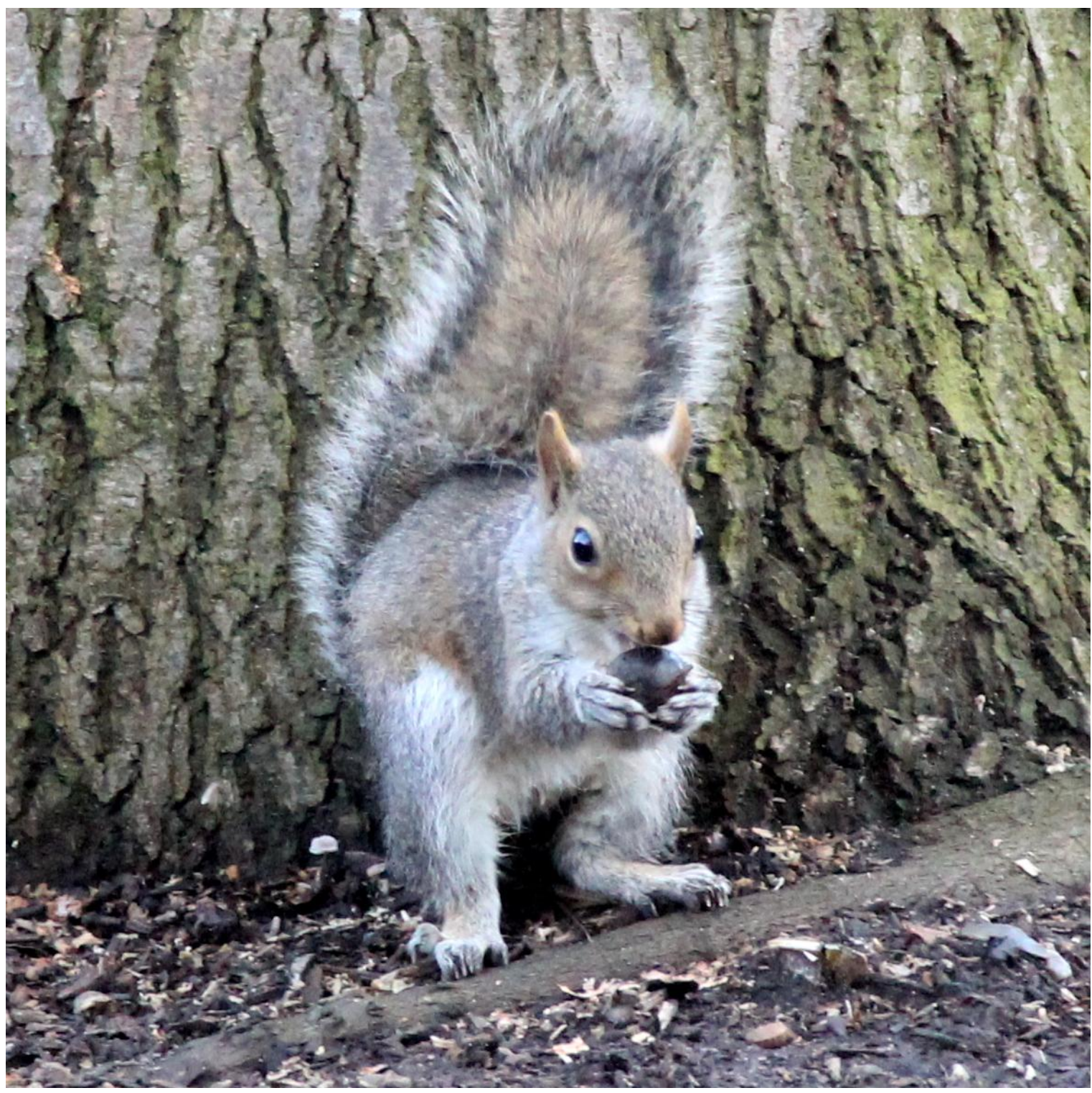

Figure 4. The grey Squirrel has tried to eat nut, this photo was taken on $22^{\text {nd }}$ of December 2013 at 15:30.

Furthermore, each method has own bias toward the observing the squirrel, for instance in line transect; most of time used path and road to do the survey and would impact on the activity of squirrel because this road used by people such as dog walker as I faced this problem in my project and have effect on detectability and activity of grey squirrel during survey (Sutherland.W.J. 2006). Therefore, the grey squirrel density (31 gray squirrel/ ha) by point count higher than density of squirrel by line transects methods (15 gray squirrel/ ha). However, the result of t-test of mean of grey squirrel where counted by both methods show that there are not differences between them $\left(\mathrm{t}_{(10)}=0.542, \mathrm{P}>0.05(\mathrm{p}=0.599)\right.$ (Figure 3.), i.e. the line transect and point count are not significant different from each other to estimate 
density of grey squirrel. Thus, The results of project did not meet with the prediction of the project.

The results we obtained are specific to the species of grey squirrel we studied to estimate the density of grey squirrel to find comparison of survey methods. Although it is not straightforward to extrapolate our results to other studies, we suggest that more of these types of comparisons are needed especially used different species, so we can learn which techniques are the most efficient in each case. If more studies quantified costs it may be possible in the future to accurate the results to find the best survey methods with take less cost and time. The choice of the best technique should always consider the effort that each of the techniques will demand and resources and time available for the study.

\section{Conclusion}

There are many techniques that used to survey squirrels, two of them are line transect and point count where we used in this research. To investigate the comparison of both methods, we used grey squirrel. In this study we hypothesized that there is a differences between the lines transect and point count (Sutherland.W.J. 2006). By estimating grey squirrel (Sciurus carolinensis) in the University of East Anglia campus. This hypothesis predicts that we will see the number of squirrel observed from line transect higher than point count. The assumptions of the research are no significant outliers in the two groups of your independent variable in terms of the dependent variable, your dependent variable should be approximately normally distributed for each group of the independent variable, and you have homogeneity of variances (i.e., the variance is equal in each group of your independent variable).

The results of the study shows that the grey squirrel was more recorded in point count $(\mathrm{M}=$ $2, \mathrm{SD}=1.789)$ than line transect method $(\mathrm{M}=1.5, \mathrm{SD}=1.378)$ (Figure 3.), there is not a significant difference between point count and line transect, $\mathrm{M}=0.5,95 \% \mathrm{CI}[-1.55,2.55], \mathrm{t}$ $(10)=0.542, \mathrm{P}>0.05(\mathrm{p}=0.599)$. There are some limitations and barrier have influence on implementing the project, for instance the climates variables have effect on the activity of grey squirrel. Squirrels are unlikely to be very active in heavy rain, strong winds or when it is very cold for instance temperature, especially in the winter season, when my project was done in December, Also the grey squirrel is strictly a diurnal species (Thompson 1977).

I believe that the comparison of survey techniques is required because of some project need a big budget, have limitations, barrier and technical requirement therefore to minimized these requirements should be choose the best technique. According to our results there is no significant difference between line transect and point count to survey grey squirrel.

\section{Acknowledgement}

The author wish to thanks Dr. Diana Bell, Dr. Simon Buttler, Dr. Iain Barr, for helping me to understand the ecological survey methods principle and filed work and Dr. Jenny Gill to explained for me the design of the experiment and her advices to do the project in the best way. Also I wanted to thanks my colleges, especially Wael, who helped me in this project. Finally I wanted to thanks Biological school and Kurdistan Region Government to fund me to do this project. 


\section{References}

Barkalow Jr, F. S., et al. (1970). The vital statistics of an unexploited gray squirrel population. The Journal of Wildlife Management, 34(3), 489-500. http://doi.org/10.2307/3798852

Barker, J. M., \& R. Boonstra (2005). Preparing for winter: divergence in the summer-autumn hematological profiles from representative species of the squirrel family. Comp Biochem Physiol A Mol Integr Physiol, 142(1), 32-42. http://doi.org/10.1016/j.cbpa.2005.07.003

Buckland, S. T., et al. (2004). Advanced distance sampling: estimating abundance of biological populations, Oxford University Press Oxford.

Charles E. Gates, W. H. M. a. D. P. O. (1968). Line Transect Method of Estimating Grouse Population Densities, 24(1), 135-145. http://doi.org/10.2307/2528465

Flyger, V. F. (1959). A comparison of methods for estimating squirrel populations. The Journal of Wildlife Management, 23(2), 220-223. http://doi.org/10.2307/3797645

Gurnell J, L. P., McDonald R., \& Pepper H. (2009). Practical techniques for surveying and monitoring $\quad$ squirrels. Reterived from http://wwww.forestry.gov.uk/PDF/fcpn011.pdf/\$FILE/fcpn011.pdf

Hayne, D. W. (1949). An examination of the strip census method for estimating animal populations. Journal of Wildlife Management, 13, 145-157. [Online] Available: http://www.jstor.org/stable/3796084 (April 24, 2016)

Healy, W. M., \& C. J. Welsh (1992). Evaluating line transects to monitor gray squirrel populations. Wildlife Society Bulletin: 83-90. [Online] Available: http://www.jstor.org/stable/3782764

Hein, E. W. (1997). Demonstration of line transect methodologies to estimate urban gray squirrel density. Environmental Management, 21(6), 943-947. http://doi.org/10.1007/s002679900078

Nixon, C. M., et al. (1975). Effects of hunting and mast crops on a squirrel population. The Journal of Wildlife Management: 1-25. http://doi.org/10.2307/3800460

Okubo, A., et al. (1989). On the Spatial Spread of the Grey Squirrel in Britain. Proceedings of the Royal Society B: Biological Sciences, 238(1291), 113-125. http://doi.org/10.1098/rspb.1989.0070

Southwood, T. R. E., \& P. A. Henderson, Eds. (2000). Ecological Methods. Lineacre Professor of Zoology, University of Oxford, South Parks Road, Oxford, Blackwell Science Ltd.

Sutherland. W. J., Ed. (2006). Ecological Census Techniques. The Edinburgh Building, Cambridge, UK, Cambridge University Press.

Tattoni, C., et al. (2006). Modelling the Expansion of a Grey Squirrel population: Implications for Squirrel Control. Biological Invasions, 8(8), 1605-1619. 
http://doi.org/10.1007/s10530-005-3503-z

Thompson, D. C. (1977). Diurnal and seasonal activity of the grey squirrel (Sciurus carolinensis). Canadian Journal of Zoology, 55(7), 1185-1189. http://doi.org/10.1139/z77-153

\section{Copyright Disclaimer}

Copyright for this article is retained by the author(s), with first publication rights granted to the journal.

This is an open-access article distributed under the terms and conditions of the Creative Commons Attribution license (http://creativecommons.org/licenses/by/3.0/). 